Proc. Indian Acad. Sci. (Earth Pianet. Sci.), Vol. 101, No. 3, September 1992, pp. 283-298. (C) Printed in India.

\title{
Anomalous granulite crust of South India - signatures from converted teleseismic waves
}

\author{
D S RAMESH, D SRINAGESH, S S RAI and K S PRAKASAM \\ National Geophysical Research Institute, Uppal Road, Hyderabad 500007, India
}

MS received 19 November 1991; revised 3 August 1992

\begin{abstract}
Analysis of teleseismic waves using $S-P$ converted phases, travel time-terms and residual travel times point to the presence of an anomalous thick (4-5 km thicker) low velocity $(-3 \%)$ crust beneath Kodaikanal (KOD) on granulites characterized by an oriented inhomogeneity inferred as possibly due to Mylonites in contrast to the nature of crust beneath the adjoining precambrian granite-gneiss terrain. The observed seismic signatures in the South India granulites (represented by KOD) offer an opportunity to discriminate between the competing hypotheses of tectonic thickening and magmatic underplating to explain the origin of the granulites of South India. This analysis lends support to the hypothesis of a continent-continent collision origin for the granulites in the study region.
\end{abstract}

Keywords. Anisotropy; collision tectonics; converted phases; granulites.

\section{Introduction}

The South Indian granulite terrain, covering thousands of square kilometers, starts roughly at $12^{\circ} 45^{\prime} \mathrm{N}$ latitude (figure 1 ) and continues down south to the tip of the South Indian Peninsula. A variety of scientific investigations have been carried out over these high grade metamorphic rocks with a view to evolving a tectonic model to explain the origin of these exposed lower crustal rocks (Pichamuthu 1953; Drury et al 1984; Newton and Hansen 1986).

The models describing the evolution of high grade metamorphic terrains are generally known to follow two mechanisms classified as (Furlong and Fountain 1986; Mezger et al 1990): (a) Consequence of tectonic thickening (b) Addition of mantle derived magma at the base of the crust (magmatic underplating).

In general, geophysical signatures, mainly seismic and gravity together, of these competing models could be fortunately diverse and hence it becomes possible to discern between these hypotheses. The seismic travel-time response over a terrain following the model of tectonic thickening due to continental convergence is essentially characterized by observations of anomalous travel time delays due to the presence of a thick crust underlain by a low velocity uppermost upper mantle as a consequence of collision (Taylor and Toksoz 1977). Modelling of magneto-telluric and seismic reflection data from continent-continent collision zones show the presence of low veolcity (Hyndman and Shearer 1989) to intermediate velocities (Fountain and Salisbury 1981) in the lower crust.

The results obtained from 3-D tomographic imaging of the granulite terrain (Rai et al 1992), reveal the presence of an anomalously thick low velocity crust 


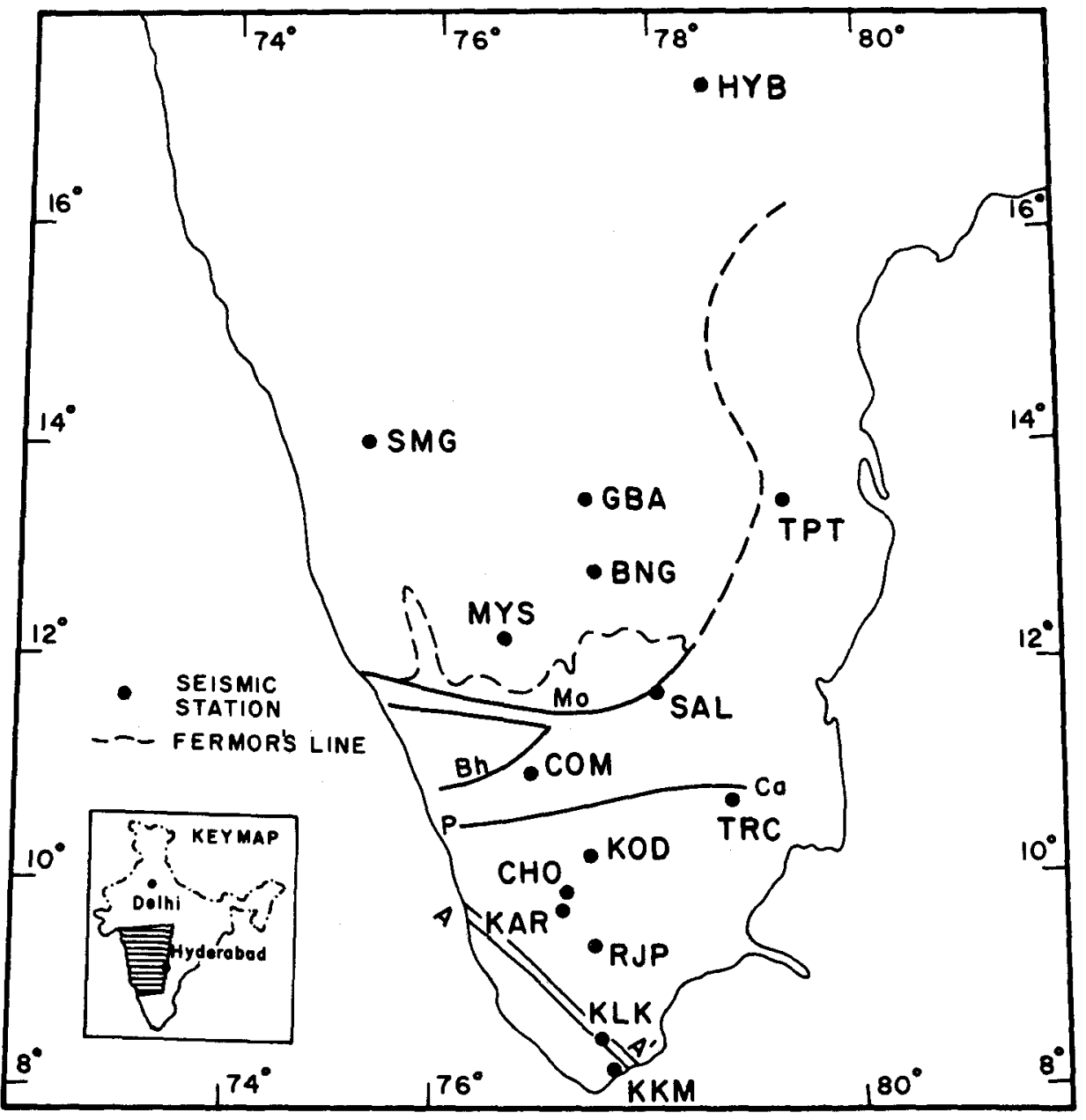

Figure 1. Map showing the granulite terrain of South India with shear zones. Circles indicate location of seismic stations with their names in three letter codes. A-A' is Achankovil lineament, $\mathrm{P}-\mathrm{Ca}$ is Palghat-Cauvery shear and $\mathrm{Mo}-\mathrm{Bh}$ is Moyar-Bhavani shear. Fermor's line is the boundary separating the low and high-grade terrains.

underlain by a low velocity uppermost upper mantle suggesting a Precambrian continent-continent collision origin of these southern granulites of India. Gravity studies in the South India granulites indicate a progressive crustal thickening from the low grade terrain in the north to the high grade terrain in the south (Subba Rao 1987; Mishra 1990).

The model of magmatic underplating to explain formation of granulites is usually reflected by the presence of a thick but high velocity lower crust (Furlong and Fountain 1986) due to accretion of magmatic material to the base of the crust derived from mantle reservoir in sharp contrast to the signatures of the alternate model suggested above. 


\section{Scope of the paper}

The present study emphasizes the evaluation of teleseismic signatures in the high grade terrain of South India using time-term, travel time, anisotropy and waveform analysis. The geophysical results from South India granulites show the presence of an anomalously thick crust with a low velocity uppermost upper mantle that were argued as'a support for a Precambrian continent-continent collision origin of the granulites (Rai et al 1992). Additional evidence for this hypothesis can be found by looking for seismically detectable crustal mylonite zones. Hsu (1979) and Trumpy (1980) show that such suture zones are characterized by the presence of mylonites, which are rocks of various compositions that are distinctly layered with planar geometry and which exhibit strong fabric or preferred orientation of minerals because of shearing. The various hypotheses (Hsu 1979; Trumpy 1980; Newton and Perkins 1982) proposed to explain crustal thickening through crustal scale deformations involve movement of crustal size blocks and perhaps the underlying uppermost upper mantle over considerable distances. Such large-scale ductile deformations involving shearing can generate strong fabric or mineralogical orientations reflected as oriented inhomogeneities and anisotropy. The mylonites characterised by the above features/ properties can be detected by observing the azimuthally varying component of the teleseismic residual (Dziewonski and Anderson 1983) and direct observation of the phenomenon of shear wave splitting of teleseismic SKS waveform (Vinnik et al 1984; Kind et al 1985; Silver and Chan 1988).

We substantiate the presence of mylonites in the region using azimuthally varying teleseismic residual and anisotropy, and proceed to support the hypothesis of tectonic thickening by determining an anomalous thick crust beneath the granulite terrain. Accurate crustal thickness estimates can be obtained from analysis of converted body waves $\left(S_{p}, P_{s}\right)$ (Jordan and Frazer 1975; Burdick and Langston 1977) recorded by three-component seismic stations. We adopt analysis of $S-S_{p}$ differential travel times, since they happen to be most sensitive to crustal thickness with weaker dependence on the average compressional wave velocities (Jordan and Frazer 1975). We present an analysis of three-component seismograms recorded at the WWSSN station Kodaikanal (KOD) located in the heart of granulite terrain, which reflects the general character of the high grade terrain. Crustal thickness estimates in the south Indian shield are also presented which are based on station anomaly data and velocity perturbations obtained from seismic stations in the region.

\section{Time term analysis}

The observed travel time residual at a station relative to Jeffreys-Bullen travel time curves is the combined effect of path, source term and heterogeneity immediately beneath the station (station term). The station term $d$ from an azimuth $\phi$ has static and azimuthally varying terms (Dziewonski and Anderson 1983) expressed as:

$$
d=A_{0}+A_{1} \cos \left(\phi-E_{1}\right)+A_{2} \cos \left(\phi-E_{2}\right)
$$


Table 1. Time-term magnitudes of the static term $A_{0}$ and the first azimuth dependent term $A_{1}$ reflecting the structural inhomogeneity. (After Dziewonski and Anderson 1983).

\begin{tabular}{|c|c|c|c|c|c|c|}
\hline \multirow[b]{2}{*}{ Station name } & \multirow[b]{2}{*}{ Station code } & \multicolumn{3}{|c|}{ Magnitudes } & \multicolumn{2}{|c|}{$\begin{array}{l}\text { Slow directions } \\
\text { angles measured } \\
\text { clockwise from north }\end{array}$} \\
\hline & & $\begin{array}{c}\text { Azimuth } \\
\text { independent } \\
\text { term } \\
A_{0}\end{array}$ & $\begin{array}{c}\text { First } \\
\text { azimuthal } \\
\text { term } \\
A_{1}\end{array}$ & $\begin{array}{c}\text { Second } \\
\text { azimuthal } \\
\text { term } \\
A_{2}\end{array}$ & $\begin{array}{c}\text { First } \\
\text { azimuthal } \\
\text { term } \\
E_{1}\end{array}$ & $\begin{array}{c}\text { Second } \\
\text { azimuthal } \\
\text { term } \\
E_{2}\end{array}$ \\
\hline BOKARO & BOK & +0.76 & 0.45 & - & 103 & - \\
\hline DEHRADUN & DDI & +0.29 & 0.43 & 0.20 & 330 & 126 \\
\hline NEW DELHI & NDI & -0.30 & 0.49 & 0.02 & 288 & 148 \\
\hline SHILLONG & SHL & -0.57 & 0.53 & 0.24 & 167 & 22 \\
\hline BOMBAY & BOM & +0.74 & $1 \cdot 10$ & 一 & 200 & - \\
\hline GAURIBIDANUR & GBA & $+0 \cdot 10$ & 0.17 & $0 \cdot 31$ & 130 & 109 \\
\hline HYDERABAD & HYB & -0.25 & 0.22 & 0.13 & 175 & 101 \\
\hline KODAIKANAL & KOD & +0.89 & 0.61 & 0.08 & 185 & 105 \\
\hline MADRAS & MDR & $+1 \cdot 11$ & 0.37 & - & 182 & - \\
\hline POONA & POO & +0.05 & 0.35 & 0.15 & 270 & 117 \\
\hline
\end{tabular}

The coefficients $A_{0}, A_{1}, A_{2}$ and directions $E_{1}, E_{2}$ are given in table 1 after accounting for station elevation is obtained through least squares inversion of $P$-wave residuals at all WWSSN and IMD Indian stations by Dziewonski and Anderson (1983). Details of nature of computations, errors, azimuthal distribution and other specific details are described by them. The static effect $A_{0}$ is azimuth independent and the first azimuth dependent term $A_{1}$ depends on major crustal and upper mantle lateral heterogeneities (Dziewonski and Anderson 1983). We compare the $A_{0}$ and $A_{1}$ terms (table 1) for the station KOD in the granulite terrain with Hyderabad (HYB) and Gauribidanur (GBA) in the peninsular gneiss.

The character and magnitude of $A_{0}$ term reflects mainly the nature and strength of crustal anomaly (Dziewonski and Anderson 1983). The value of $A_{0}$ at KOD is $+0.89 \mathrm{~s}$ which shows the slower nature of crust there in comparison to GBA and HYB where the values of $A_{0}$ are $+0.1 \mathrm{~s}$ and $-0.15 \mathrm{~s}$ respectively.

To explain the $A_{0}$ term fully at $\mathrm{KOD}$, assuming a normal crust of $35 \mathrm{~km}$ as at GBA, a simple calculation reveals that we require either presence of an abnormal crustal thickening of $24 \mathrm{~km}$ or presence of an unrealistic low velocity crust, about $-15 \%\left(V_{p}\right)$, below $\mathrm{KOD}$ compared to GBA with an average crustal velocity of $6.4 \mathrm{~km} / \mathrm{s}$ and $8.2 \mathrm{~km} / \mathrm{s}$ of upper mantle velocity. Both the above estimates at KOD are unrealistic.

The different nature of the granulite terrain as compared to the granite-gneiss terrain is further substantiated by the anomalous magnitude of $A_{1}$ term at KOD $(0.61 \mathrm{~s})$ compared to HYB $(0.22 \mathrm{~s})$ and GBA $(0.17 \mathrm{~s})$ (table 1$)$. Thus a significant contribution to the residual at KOD is due to azimuthally dependent inhomogeneity apart from the static effect. Such an oriented inhomogeneity would cause prominent shear wave splitting and can thus be detected. 


\section{Shear wave anisotropy}

In the presence of an anisotropic zone, a linearly polarized incoming shear wave would split into two orthogonally polarized shear waves travelling with different velocities. This would result in a time delay between the arrival of these split waves in the horizontal components depending upon the direction and magnitude of velocity anisotropy.

The applicability of shear wave splitting analysis to WWSSN type data has been demonstrated by Vinnik et al (1989) using the Grafenburg array (GFA) data. Further, the detectability of the property of shear wave splitting in the long period range is confirmed by us from the data of DWWSSN station RSSD in North America where fast anisotropic axis directions $\left(54^{\circ} \pm 8^{\circ}\right)$ are available (Silver and Chan 1988) from broad-band data. Adopting our data processing techniques, mentioned below, to Digital WWSSN data at RSSD we were able to retrieve similar fast directions $\left(54^{\circ} \pm 9^{\circ}\right)$, within the limits of error, as reported through broad band measurements. To investigate the possible existence of shear wave splitting due to anisotropy in the high grade terrain in South India and the nature of its difference as compared to the low grade (Peninsular gneiss), we have studied the seismograms from WWSSN stations at KOD (high grade terrain) and HYB (low grade terrain).

In this study SKS phases which were well isolated from $\mathrm{S}$ and $\mathrm{ScS}$ and sufficiently energetic for visual observations from 9 events (table 2) were analysed. The seismograms from WWSSN stations KOD and HYB were magnified four times and digitized at a sampling interval of $0.25 \mathrm{~s}$. The digitized seismograms were compared with the originals to check their accuracy. They were passed through a Gaussian bandpass filter in the range $6-14 \mathrm{~s}$. The shear wave splitting due to anisotropy is manifested through the elliptic nature of particle motion of the observed horizontal components because of the phase difference induced by anisotropy. Another diagnostic of shear wave splitting is the presence of a significant amount of SKS energy in the transverse component $(T)$ with its predominant presence in the radial component $(R)$.

Table 2. List of events used at HYB and KOD for shear wave splitting studies.

\begin{tabular}{|c|c|c|c|c|c|c|c|c|c|c|}
\hline \multirow[b]{3}{*}{$\begin{array}{l}\text { Event } \\
\text { No. }\end{array}$} & \multirow{2}{*}{$\begin{array}{c}\text { Station } \\
\begin{array}{c}\text { Hyderabad } \\
\text { Kodaikanal }\end{array}\end{array}$} & \multicolumn{3}{|c|}{ Code } & \multicolumn{2}{|c|}{ Latitude } & \multirow{2}{*}{$\begin{array}{c}\text { Longitude } \\
77 \cdot 44^{\circ} \mathrm{E} \\
77 \cdot 47^{\circ} \mathrm{E}\end{array}$} & \multicolumn{2}{|c|}{ Geology } & \multirow[b]{3}{*}{ Station } \\
\hline & & \multicolumn{3}{|c|}{$\begin{array}{l}\text { HYB } \\
\text { KOD }\end{array}$} & \multicolumn{2}{|c|}{$\begin{array}{l}17.41^{\circ} \mathrm{N} \\
10 \cdot 23^{\circ} \mathrm{N}\end{array}$} & & \multicolumn{2}{|c|}{$\begin{array}{l}\text { Precambrian } \\
\text { Charnockites }\end{array}$} & \\
\hline & Date & & $\begin{array}{l}\text { Tim } \\
\text { Mir }\end{array}$ & Sec & $\begin{array}{l}\text { Lat. } \\
\text { (Deg) }\end{array}$ & $\begin{array}{l}\text { Long. } \\
\text { (Deg) }\end{array}$ & $\begin{array}{l}\text { Depth } \\
(\mathrm{km})\end{array}$ & $\begin{array}{c}\text { Distance } \\
\text { (Deg) }\end{array}$ & $\begin{array}{l}\text { Azimuth } \\
\text { (Deg) }\end{array}$ & \\
\hline 1. & $\begin{array}{lll}83 & 12 & 02\end{array}$ & 03 & 09 & 05.6 & $14.07 \mathrm{~N}$ & $091.92 \mathrm{~W}$ & 067 & 144.6 & 335.6 & HYB \\
\hline 2. & 831221 & 12 & 05 & $06 \cdot 3$ & $28.19 \mathrm{~S}$ & $063 \cdot 17 \mathrm{~W}$ & 592 & $142 \cdot 9$ & $245 \cdot 3$ & HYB \\
\hline 3. & $\begin{array}{lll}84 & 10 & 20\end{array}$ & 17 & 59 & 17.0 & $24.07 \mathrm{~S}$ & $066.83 \mathrm{~W}$ & 192 & $147 \cdot 0$ & 252.5 & HYB \\
\hline 4. & 870429 & 14 & 27 & $35 \cdot 7$ & $19.00 \mathrm{~S}$ & $177.36 \mathrm{~W}$ & 385 & $108 \cdot 4$ & 104.6 & HYB \\
\hline 5. & $\begin{array}{llll}82 & 10 & 03\end{array}$ & 21 & 58 & $44 \cdot 5$ & $56 \cdot 10 \mathrm{~S}$ & $027 \cdot 40 \mathrm{~W}$ & 105 & 106.7 & $214 \cdot 4$ & KOD \\
\hline 6. & 840928 & 00 & 03 & 34.5 & $25.85 \mathrm{~S}$ & $175.91 \mathrm{~W}$ & 021 & $109 \cdot 3$ & 113.8 & KOD \\
\hline 7. & $\begin{array}{lll}84 & 09 & 11\end{array}$ & 07 & 16 & $35 \cdot 1$ & $15.50 \mathrm{~S}$ & $167.69 \mathrm{E}$ & 126 & 092.9 & $105 \cdot 1$ & KOD \\
\hline 8. & $\begin{array}{lll}84 & 09 & 17\end{array}$ & 09 & 08 & 48.8 & $32 \cdot 16 \mathrm{~S}$ & $178.32 \mathrm{~W}$ & 010 & $107 \cdot 4$ & 120.5 & KOD \\
\hline 9. & $8605 \quad 26$ & 18 & 40 & $44 \cdot 2$ & $21.82 \mathrm{~S}$ & $179.08 \mathrm{~W}$ & 583 & $106 \cdot 1$ & $109 \cdot 8$ & KOD \\
\hline
\end{tabular}




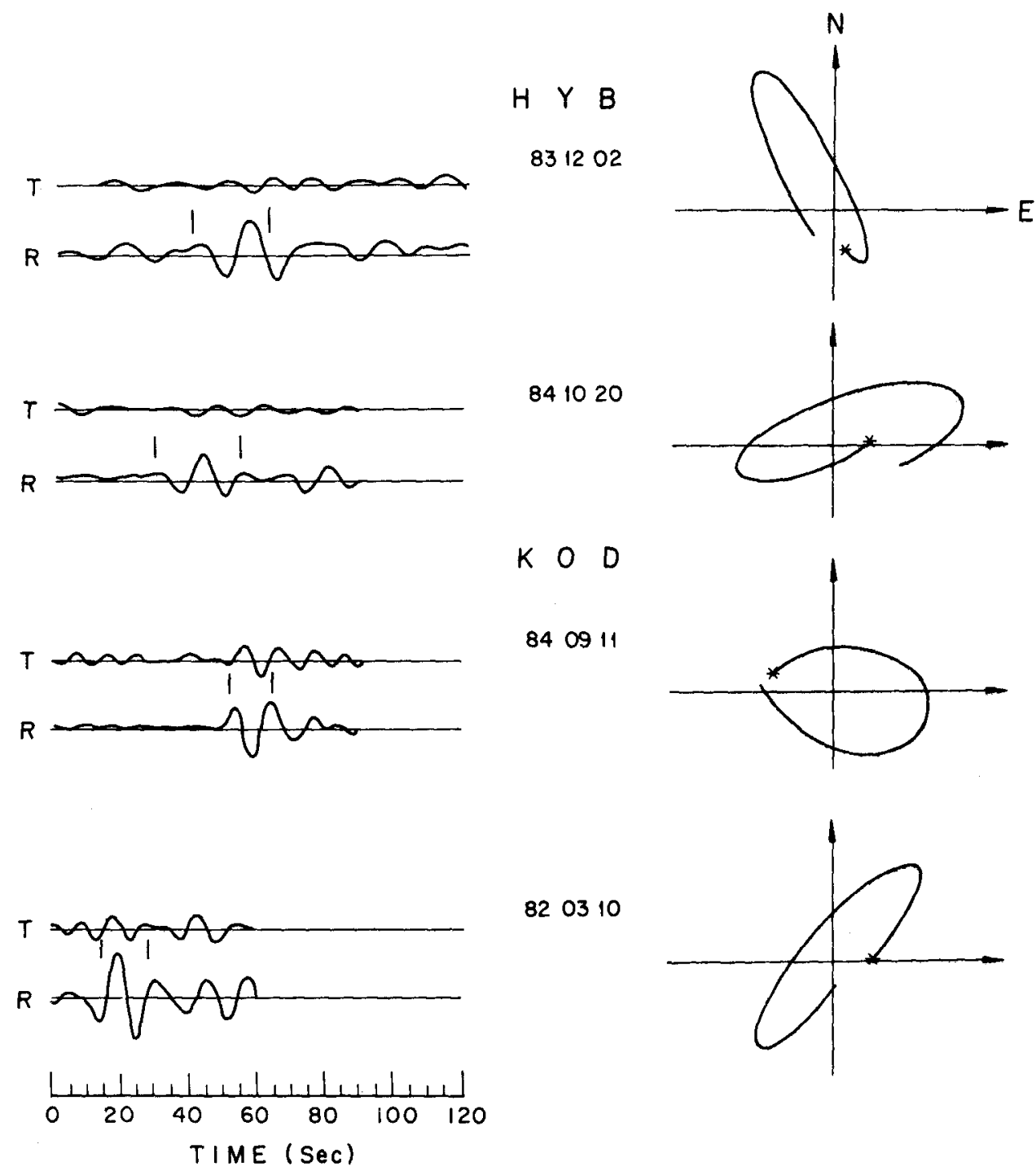

Figure 2. Radial $(R)$ and transverse $(T)$ component seismograms of sample events with their corresponding particle motion plots at HYB \& KOD for SKS phase. Vertical bars indicate duration of the SKS. Note the phase shift in SKS phase between R \& T components due to the presence of anisotropy.

This is so, since the SKS phase is an $S V$-polarised wave and in an isotropic medium should essentially appear in the radial component only. Any departure from this would result in energy in the $T$ component. Detailed analysis of anisotropy at HYB is presented elsewhere (Ramesh et al 1990). In figure 2 we present the filtered $R \& T$ seismograms together with the particle motion plots for HYB and KOD depicting the diagnostics of anisotropy mentioned above. Time delay $(\delta t)$ (arrival time difference of the SKS phase in $R \& T$ components) at KOD is about 0.85 s while at HYB is 1.4s. The averaged fast polarisation directions (FPD) after considering results from few combination of events (table 2) at HYB and KOD turn out to be about $\mathrm{N} 20^{\circ} \mathrm{E}$ and 
HYB

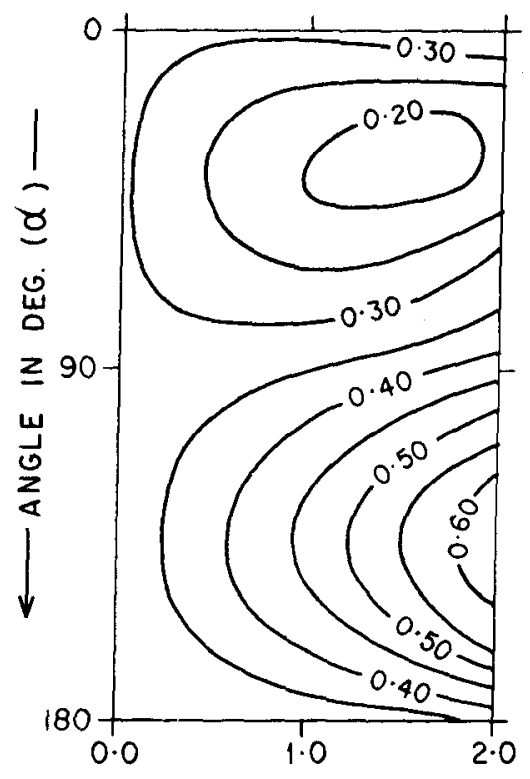

KOD

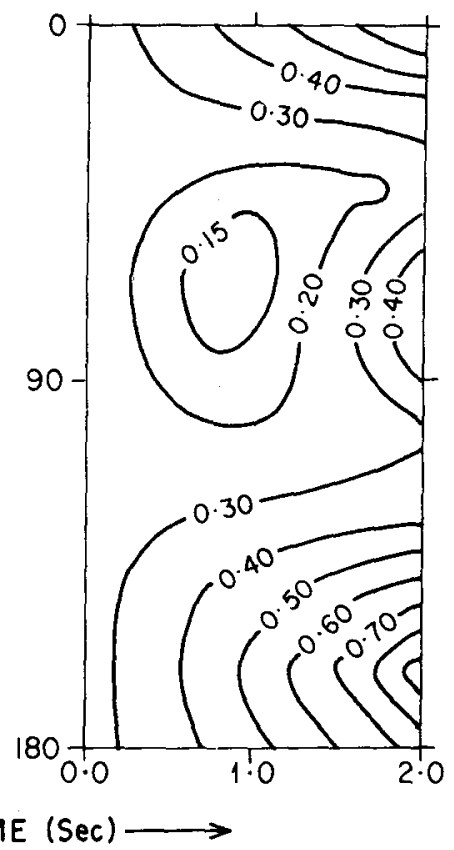

Figure 3. Energy function $\mathrm{E}(\alpha, \delta t)$ plots at HYB and KOD showing the contours of residuals for combinations of $(\alpha, \delta t)$. The contour of minimum residual gives the optimal parameters $(\alpha, \delta t)$, with spreads, defining the solution at each station.

$\mathrm{N} 60^{\circ} \mathrm{E}$ respectively (figure 3 ). It is important to observe the positive correlation at HYB between FPD ( $\left.20^{\circ} \mathrm{E}\right)$, maximum horizontal compressive stress direction (MHS) NNE and present day absolute plate motion direction (APM) near N-S overlap within limits of error and enable us to argue for APM related basal shear stresses as the source of anisotropy. However, no such correlation exists at KOD and hence needs special attention.

The slow direction of the second azimuthal term $\left(E_{2}\right)$ bears an important relationship to the direction of mantle flow which can be used as a tool to investigate anisotropy of the mantle (Dziewonski and Anderson 1983) related to plate motion. The fast direction of $E_{2}$, perpendicular to the slow direction of $E_{2}$ given in table 1, at HYB, GBA and KOD are remarkably coherent (N-NNE). This fast direction of $E_{2}$ has a positive correlation with the present day plate motion direction which is also observed in North America. The $E_{1}$ term too at these locations is very consistent and coherent.

The corresponding values of $A_{1}$ and $A_{2}$ at KOD and HYB (table 1) while bringing out the anomalous nature of KOD also seem to suggest that the magnitude of anisotropy $\left(A_{2}\right)$ related to flow in the mantle could be marginal or almost non existent at KOD compared to those in the low grade terrain. The observed NW MHS directions from three locations in the South India granulites (SIG) are at variance with the NNE direction in the low grade terrain (Gowd et al 1992) that closely follow present day APM direction suggesting that the nature of stresses in SIG have a different origin. 
Also the $\mathrm{N} 60^{\circ} \mathrm{E}$ FPD inferred from shear wave anisotropy at $\mathrm{KOD}$ requires to be explained invoking a source other than the present day APM.

\section{Cause of seismic anisotropy at KOD}

The cause of observed seismic anisotropy, in Precambrian high grade (granulite) terrain in contrast to the low grade (granite-gneiss) could be classified as due to compositional variation, high strain or presence of mylonites (Jones and Nur 1982; Wong et al 1982). Compositionally granulites are similar to the granite gneiss but for the addition of a high pressure-temperature mineral orthopyroxene. Thus any excess anisotropy in the granulite terrain, which may be attributed to compositional difference, could be primarily due to the presence of orthopyroxene. In orthopyroxene, anisotropy for $V_{p}$ is large $(16 \%)$, but for $V_{s}$ it is small $(5 \%)$ (Nicolas and Christensen 1987). To generate $0.85 \mathrm{~s}$ of delay time in shear anisotropy, approximately $70 \mathrm{~km}$ thick orthopyroxene layer with $5 \%$ anisotropy would be needed according to the equation:

$$
H=d t V_{s} / c
$$

where $H$ is the estimated thickness of anisotropic layer in $\mathrm{km}, d t$ the delay time in seconds, $V_{s}$ the shear wave velocity $(4.6 \mathrm{~km} / \mathrm{s})$ and $c$ the \% anisotropy $(5 \%)$. Existence of such a coherent thick zone of pure orthopyroxene is unreasonable and rather difficult to visualize.

The other source for anisotropy at KOD could be the presence of mylonites along the shear or deep faults. Mylonites are the product of shearing in crystalline rocks generally confined to crustal levels and show significant velocity anisotropy $(6-17 \%)$ even at high pressure $(600 \mathrm{MPa})$ due to preferred mineral orientation (Siegesmund and Kern 1990). The region encompassing KOD is sandwiched between two major shear zones namely the Moyar-Bhavani in the north and the Achankovil in the south (figure 1). Exposed mylonite zones have also been reported along these major shear zones and just north of KOD (Drury et al 1984; Gopalakrishnan et al 1990).

The model of southward subduction of the Dharwar block underneath the granulite terrain (Rai et al 1992) could explain the formation of mylonites at mid-crustal shear zones which should be present under the KOD block. This would in turn give rise to anomalous anisotropic signatures as observed at KOD. As these mylonites are generally confined to crustal level deformations, it appears reasonable to expect a significant contribution from the crust beneath KOD to the observed anisotropic delay time $(\delta t)$ of $0.85 \mathrm{~s}$ and the anomalous value of $A_{1}(0.61 \mathrm{~s})$. An exact estimate of the crustal contribution can however be made from analysis of $\mathrm{PmS}$ converted phase at the Moho.

Experimental studies on varying compositions of mylonites (Siegesmund and Kern 1991$)$ besides yielding a range of anisotropic values $\left(4-15 \%\right.$ for $V_{p} ; 6-17 \%$ for $\left.V_{s}\right)$ also yield a broad range of $V_{p}(5.98-7.07 \mathrm{~km} / \mathrm{s})$ and $V_{s}(3.62-4.14 \mathrm{~km} / \mathrm{s})$ values. Hence, we refrain from computing the mylonite thickness at KOD from the delay times but recognize that mylonites at KOD do contribute significantly to the $A_{1}$ term besides showing up anomalously in the shear wave splitting at this location.

The other parameter of anisotropy, $\mathrm{N} 60^{\circ} \mathrm{E}$ fast polarisation direction (FPD), at $\mathrm{KOD}$ is at variance with the predicted FPD related to present day plate tectonic 
deformation forces and the measured coherent NNE (Gowd et al 1992) maximum horizontal compressive stress direction (MHS) in a major part of the Indian shield. From the knowledge of geologic fabric orientation and anisotropy the measured in-situ stress compressive directions that differ from present day principal stress axis are interpreted in terms of paleo or remanent paleo stresses related to Archaean/early Proterozoic deformation in preference to present day active stress as observed in a region in Canada (Brown et al 1990). Such an interpretation is reasonable as the elastic energy must have been locked-in inter-granularly at the time of formation of the geologic structures in the region from the then existing stresses which would now be reflected as residual paleo-stress. Due to lack of any correlation between FPD and present day tectonic processes at KOD, we turn to 'fossil' or paleo anisotropic signatures as a possible source to explain the observed $\mathrm{N} 60^{\circ} \mathrm{E}$ FPD. The regional surface geology in the SIG show an early geologic fabric roughly ENE almost following the trend of Fermor's line and the relatively younger mega shears showing dominant E-W strike (Drury et al 1984). The older ENE geologic strike is stronger and pervasive, perhaps the most significant deformation in the region due to near NW-SE compression event imparting the observed NE to ENE extension direction in the SIG. The observed NW MHS at three locations in the SIG at variance with present day MHS direction (N-NNE) may be a possible reflection of these 'fossil' stresses predicted by the geologic fabric orientation and also measured as the ENE extension (FPD) direction at KOD. Such large scale compressive forces can indeed be generated by collision on continental scales. Besides, presence of a relatively gentle topography in the low grade terrain compared to the highly deformed nature of the high grade region with presence of mylonites and mega shears characteristic of suture zones together with elevations reaching as high as $2.6 \mathrm{~km}$ point out that the granulites might have formed as a consequence of continent-continent collision with the 'Dharwarian plate' subducting southwards. Such a model predicts progressive southward thickening of the crust from the low grade to the high grade terrain characterised by low velocity. Though collision is our preferred model to interpret anisotropy, an alternate model to explain the observed $\mathrm{N} 60^{\circ} \mathrm{E}$ (ENE) FPD at KOD without invoking collision exists but has little to offer in terms of model predictions that can explain the formation of granulites. This model suggests that the observed predominent ENE trends in the SIG are a product of an early deformation that perhaps predates even 2.6 b.y. The EW to ENE structural trends in the Dharwar province are related to the early isoclinal folds. Around $2 \cdot 5$ b.y. $-2 \cdot 6$ b.y. these folds have been involved in non-coaxial open to tight folding, refolding the early folds along the presently observed NNW-NNE directions (Naha et al 1991). A similar structural history has been inferred for the granulite terrain of Kerala and adjoining portion of Tamilnadu by Rao (1978). Therefore, the EW, ENE orientation of the early folds is associated with extremely strong compression compared to the later folds. Thereby, producing strong geologic fabric in the ENE direction which is possibly reflected in the observed ENE FPD at KOD. However, this model cannot explain several geophysical and geological signatures like a thickened low velocity crust, P-T-t paths, heat flow/generation values, variant MHS directions etc. in the SIG.

Further, the three-dimensional modelling results beneath KOD (Rai et al 1992), using the special first layer to isolate the effect of crustal anomalies, yield a velocity perturbation of $-3.9 \%$ (low velocity) due to lateral velocity heterogeneity 
in the crust, a character also reflected in the anomalous $A_{0}$ term $(0.89 \mathrm{~s})$ at KOD. Thus the anomalous nature of time-terms at KOD also reflected in shear-wave splitting and tomographic results are satisfactorily explained invoking the presence of mylonites together with a $4 \%$ low velocity anomaly at crustal level.

\section{Estimation of crustal thickness}

The estimate of crustal thickness in the granulite terrain obtained from gravity data is $43 \mathrm{~km}$ at KOD (Subba Rao 1987). A seismic crustal model at KOD using $P-S$ converted waves obtained a thickness of $40 \mathrm{~km}$ (Peseckis and Burdick 1982). Therefore we attempted to obtain crustal thickness estimates at KOD using teleseismic converted phases.

\section{Differential travel times of $S-S_{p}$ waves}

We analyse here the vertically polarised $S$-wave $(S V)$ incident at sub-critical angles near the Moho discontinuity converted to $P$-wave $\left(S_{p}\right)$. $S_{p}$ phase, preceding the $S$ phase contains the crustal information (Smith 1970; Bath and Stefansson 1966). It is well observed in the radial and vertical components of the seismogram. Following Jordan and Frazer (1975) the lead time of $S_{p}$ relative $S$ is given by:

$$
T_{s-s_{p}}=a_{s-p} \cdot L
$$

where $a_{s-p}$ is the difference between the average vertical slownesses of $S$ and $P$ waves that can be obtained from the knowledge of ray parameter $p(\mathrm{~d} T / \mathrm{d} \Delta)$ and velocities in the study region. $L$ is the total thickness to be estimated. The equation used to compute the total thickness $L$ through $a_{s-p}$ is:

$$
T_{s-s_{p}}=L\left[\left(V_{s}^{-2}-p^{2}\right)^{1 / 2}-\left(V_{p}^{-2}-p^{2}\right)^{1 / 2}\right]
$$

where $V_{p}$ and $V_{s}$ are the $P$ and $S$ wave velocities that can be adopted from various models for the region under consideration.

The data used in this study happen to be disposed in a fashion where either of the original $\mathrm{N}-\mathrm{S}$ and $\mathrm{E}-\mathrm{W}$ seismograms at the stations turn out to be near perfect radial $(R)$ depending on the source azimuth. Analysis of such seismograms (figure 4) besides reducing the task of digitization and rotation of original seismograms to obtain $R$ component, largely eliminates the errors associated with such a process. We adopted this strategy in our analysis.

Table 3 shows a comparison of the estimated crustal thicknesses from differential travel times of $S-S_{p}$ using various velocity models adopted to the region of interest for data from stations HYB and KOD. This analysis shows that KOD on the granulites is characterised by a relatively thick (4-5 km thicker) crust compared to HYB on granite-gneiss. The preferred estimates of crustal thicknesses at KOD and HYB are about $43 \mathrm{~km}$ and $37.5 \mathrm{~km}$ respectively. This is so, because, the only crustal model available for HYB is by Singh and Rastogi (1978) and the geologic similarity of Adriandacks with KOD (both are high grade terrains) prompted us to adopt the detailed crustal model of Owens (1987) in preference to Peseckis and Burdick (1982) model for this region. 


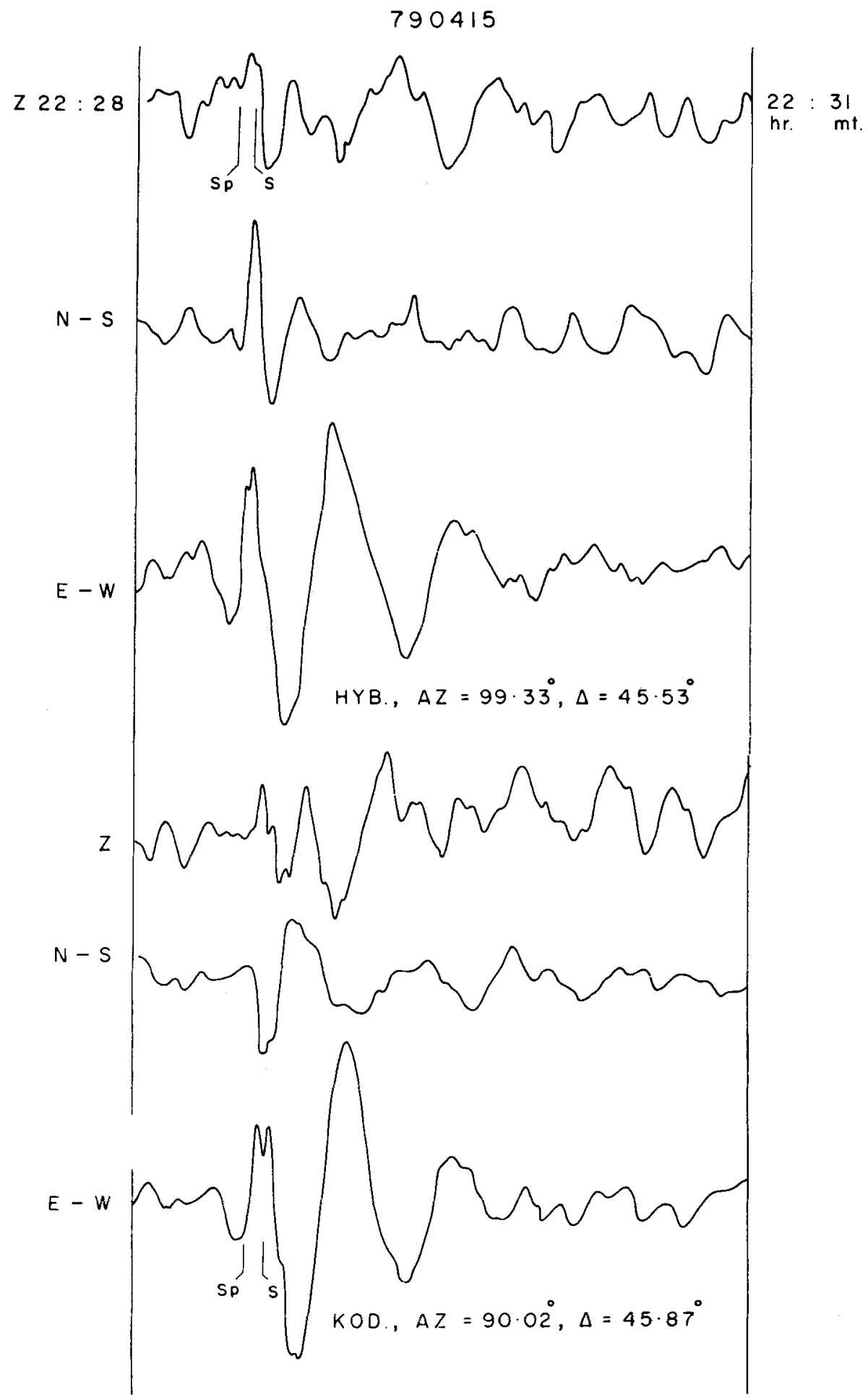

Figure 4. Original vertical, N-S \& E-W seismograms at HYB \& KOD for events (790415, 840530). Vertical bars indicate the converted $S_{p}$ phase and $S$-wave respectively. 
Table 3. Comparison of the crustal thickness estimates from $S-S_{p}$ differential travel times using various velocity models. Values with '*' 'indicate the most reliable thickness (in $\mathbf{~ k m}$ ) estimates.

\section{Estimation of crustal thickness}

Formula: $\left.T_{s-s_{p}}=L\left[V_{s}^{-2}-p^{2}\right)^{1 / 2}-\left(V_{p}^{-2}-p^{2}\right)^{1 / 2}\right]$

Poisson's ratio $=V_{p}^{2}-2 V_{s}^{2} / 2\left(V_{p}^{2}-2 V_{s}^{2}\right)$

KOD HYB

Event: MINDANO IS. Date: 790415 Time $221452 \cdot 3$ Azimuth: 92.021 99.320 Depth: $545 \mathrm{~km}$

\begin{tabular}{|c|c|c|c|c|c|c|c|}
\hline \multirow{2}{*}{$\begin{array}{l}\text { Type of } \\
\text { study }\end{array}$} & \multirow[b]{2}{*}{ Model } & \multirow[b]{2}{*}{$V_{p}, V_{s} \mathrm{~km} / \mathrm{s}$} & \multirow{2}{*}{$\begin{array}{l}\text { Poisson's } \\
\text { ratio }\end{array}$} & \multirow{2}{*}{$T_{s-s_{p}}:$} & \multicolumn{3}{|c|}{$\begin{array}{l}\text { Thickness in }(\mathrm{km}) \\
\text { KOD HYB }\end{array}$} \\
\hline & & & & & $5.2 \mathrm{~s}$ & $4.8 \mathrm{~s}$ & $5.0 \mathrm{~s}$ \\
\hline$P-S$ & $\begin{array}{l}\text { Peseckis and Burdick } \\
\text { (1982) }\end{array}$ & $6.0, \quad 3.8$ & 0.165 & & 40 & - & 一 \\
\hline$S-P$ & $\begin{array}{c}\text { Peseckis and Burdick } \\
\text { (1982) }\end{array}$ & $6.0, \quad 3.8$ & $0 \cdot 165$ & & $51 \cdot 48$ & 47.52 & $49 \cdot 50$ \\
\hline$S-P$ & $\begin{array}{l}\text { Jeffrey's and Bullen } \\
\text { (J.B. Table) }\end{array}$ & $6.2, \quad 3.9$ & 0.172 & & $51 \cdot 49$ & 47.53 & $49 \cdot 51$ \\
\hline$S-P$ & $\begin{array}{c}\text { D.S.S } \\
\text { (Kavali-Udipi Profile) }\end{array}$ & $6 \cdot 4, \quad 3.9$ & 0.204 & & $48 \cdot 15$ & 44.44 & $46 \cdot 29$ \\
\hline$S-P$ & $\begin{array}{l}\text { Adriandacks } \\
\text { (Ownes 1987) }\end{array}$ & $6.48,3.74$ & 0.249 & & $43 \cdot 29^{*}$ & 39.96 & $41 \cdot 63$ \\
\hline$S-P$ & D D Singh (1978) & $6 \cdot 27,3 \cdot 56$ & 0.262 & & $40 \cdot 63$ & $37.50^{*}$ & $39 \cdot 06$ \\
\hline
\end{tabular}

\section{Crustal thickness from teleseismic residuals}

Teleseismic residuals recorded by the seismic stations (figure 1) in South India consist of the information related to velocity variations in the crust and upper mantle along their path. The residual at each station averaged over all the events "station anomaly" primarily reflects the gross velocity variation under the station broadly reflecting the crustal contribution.

Assuming a homogeneous crust, Iyer and Healy (1972) computed the crustal thickness from the station anomaly over the LASA. Though the assumption of a homogeneous crust is valid for LASA, the combination of Precambrian orogenic belts in the modelling region of South India necessitates combining velocity variation and station anomaly together to compute crustal thickness. Thus using the velocity perturbations from the 3-D images (Rai et al 1992) of South India and station anomalies we have attempted to compute the crustal thickness and velocity parameters.

This method was successfully applied in a similar geologic scenario in NE United States (Taylor and Toksoz 1979). It is based on the assumption that the crustal velocity perturbation $\delta V / V_{c}$ is fluctuation from a reference crustal velocity $V_{c}$. The average crustal velocity beneath a station $i$ is therefore,

$$
V_{i}=V_{c}\left[1+\left(\delta V / V_{c}\right)_{i} / 100\right]
$$

and the crustal thickness is

$$
h_{i}=V_{i} R_{i}+h_{0}
$$


where $h_{0}$ is the assumed average crustal thickness and $R_{i}$ is the station anomaly. It may be noted that during the inversion, information related to absolute velocity is lost. Therefore the crustal parameters computed as above are only a first order approximation to the reality. The granulite terrain being highland region all the input data was corrected to the MSL. Average crustal velocity was assumed as $6.5 \mathrm{~km} / \mathrm{s}$ for $35 \mathrm{~km}$ thick crust. The resulting estimates of crustal thickness and average velocity are shown in figure 5(a and $b)$. The crustal thickness was found to be influenced more by the station anomaly than the obtained velocity perturbations. Also, the choice of initial crustal thickness did not change the final crustal thickness estimates. On an average, the crust beneath the granulite terrain appears to be $3 \mathrm{~km}$ thicker (figure 5a) than that of the Dharwar granite-gneiss terrain. To this estimate referenced to mean sea level, the addition of the station elevation of $2.6 \mathrm{~km}$ at KOD yields the crustal thickness estimate of about $6 \mathrm{~km}$. This estimate of relatively thicker crust beneath KOD is quite close to that obtained from differential $S-S_{p}$ travel times. The crustal velocity map (figure 5 b) shows relatively low value $(6 \cdot 2 \mathrm{~km} / \mathrm{s})$ in the granulite terrain

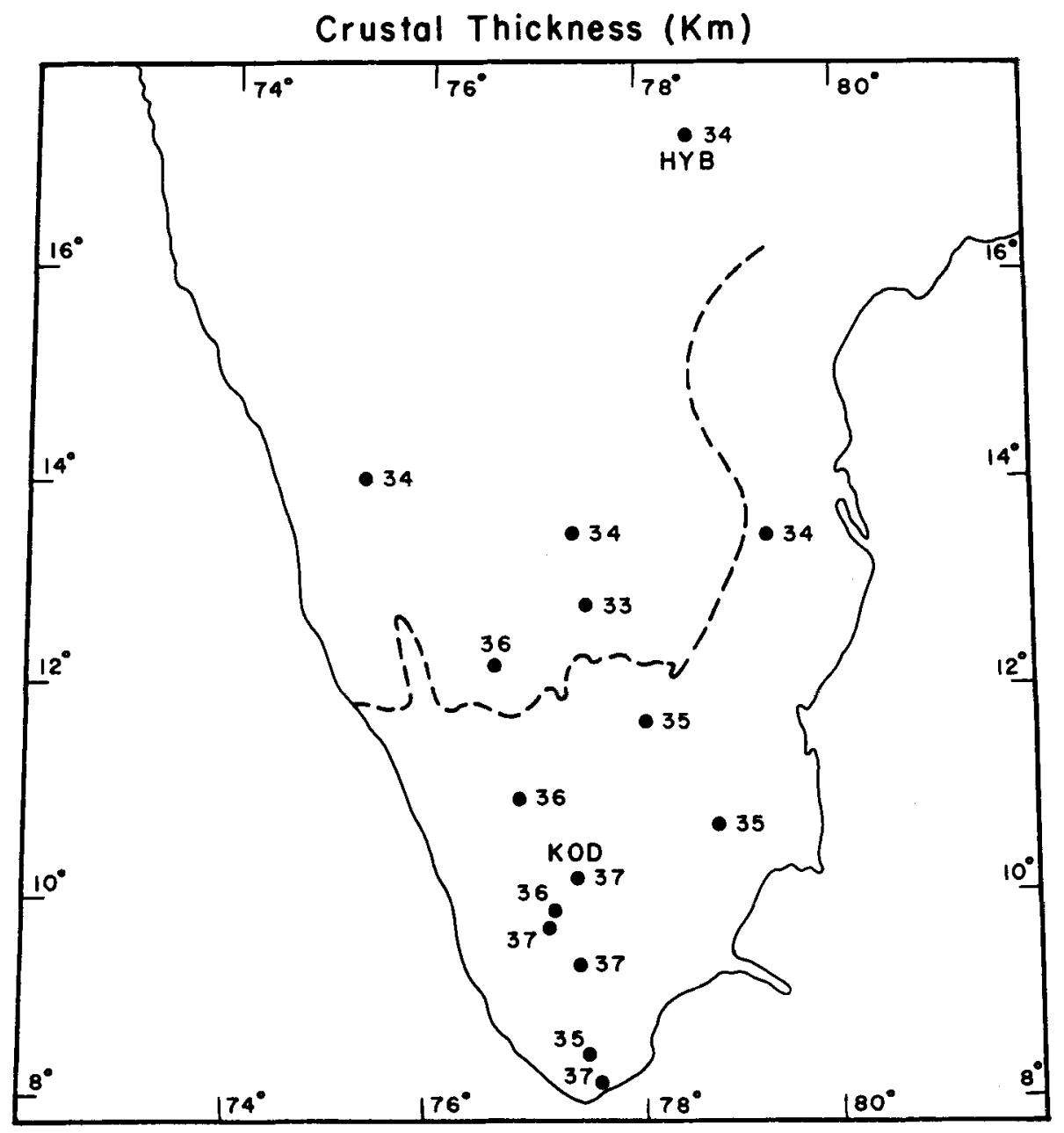

Figure 5(a). Average crustal thickness (in $\mathrm{km}$ ) in South India. 


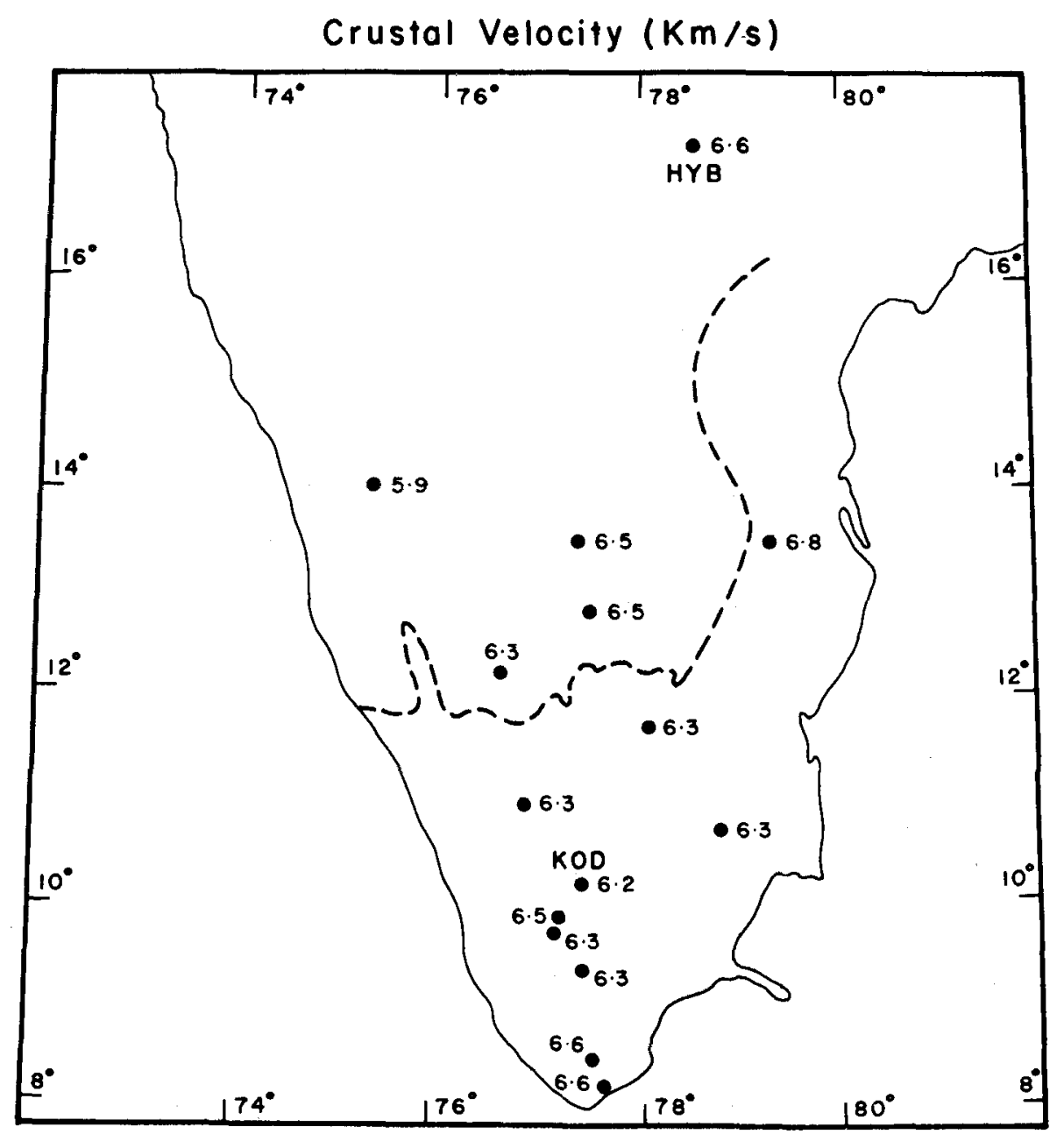

Figure 5(b). Average velocity map (in $\mathrm{km} / \mathrm{s}$ ) of South India.

as compared to the higher crustal velocity $(6.5 \mathrm{~km} / \mathrm{s})$ in the Dharwar craton (Stations GBA and BNG).

Both the above observed features, thicker crust and lower velocity, differentiate the granulite terrain from the Dharwar terrain and may be satisfactorily explained by the model requiring the presence of mylonites along thrust zones.

\section{Conclusions}

The observed abnormal average crustal thickness of about $5 \mathrm{~km}$ with an average low velocity of about $-3 \%$ in the granulites further require a significant contribution to the total delay time at KOD due to preferential fabric alignment that is best explained by the presence of mylonites at crustal depths in this region. The first azimuth dependent term, $A_{1}=0.6 \mathrm{~s}$, reflects the contribution from oriented inhomogeneity, 
like the presence of mylonites in the region, adequately explain the observed total delay time at KOD. Presence of mylonites is a characteristic feature of suture zones, areas of continent-continent collision (e.g. Alpine belt, Ivrea zone etc.). Analysis of teleseismic data at KOD, which lies on granulites, also indicates the presence of an anomalously thick, low veolcity crust characterised by mylonites. The observed $\mathbf{N}$ $60^{\circ} \mathrm{E}$ FPD at KOD with a positive correlation with the ENE dominant geologic strike direction and perpendicular to the observed anomalous NW MHS direction in the SIG together with other geophysical signatures supports the model of collision to explain formation of granulites in this region. Thus the hypothesis of a continentcontinent collision origin of the granulites of South India would explain the observations satisfactorily.

\section{References}

Bath M and Stefansson R 1966 S-P conversion at the base of the crust; Ann. Geophys. 19 119-130

Brown A, Kamineni D C and Martin C D 1990 In situ stress compared to structures in the Lac du Bonnet batholith, Manitoba, Canada; Tectonophysics 186 151-162

Burdick L J and Langston C A 1977 Modelling crustal structure through the use of converted phases in teleseismic body waveforms; Bull. Seismol. Soc. Am. 67 677-691

Drury S A, Harris N B W, Holt R W, Reeves-Smith G J and Wightman R T 1984 Precambrian tectonics and crustal evolution in south India; J. Geol. 92 3-20

Dziewonski A M and Anderson D L 1983 Travel times and station corrections of P-waves at teleseismic distances; $J$. Geophys. Res. 88 3296-3314

Fountain D M and Salisbury M H 1981 Exposed cross-sections through the continental crust: Implications for crustal structure, Petrology, and evolution; Earth Planet. Sci. Lett. 56 263-277

Furlong K P and Fountain D M 1986 Continental crustal underplating: Thermal considerations and Seismic - petrologic consequences; J. Geophys. Res. 91 8285-8294

Gopalakrishnan K, Venkata Rao V and Viswanathan T V 1990 Role of Paleosutures in the evolution of southern granulite terrain; (extended abstract), Discussion on "Suture zone- Young and Old", Wadia Institute of Himalayan Geology, Dehradun, April 1990, 55-60

Gowd T N, Srirama Rao S V and Gaur V K 1992 Tectonic stress field in the Indian subcontinent; $J$. Geophys. Res. (in press)

Hsu K J 1979 Thin skinned plate tectonics during neo-Alpine orogenesis; Am. J. Sci. 279 353-366

Hyndman R D and Shearer P M 1989 Water in the lower continental crust: Modelling magnetotelluric and seismic reflection results; Geophys. J. Int. 98 343-365

lyer H M and Healy J H 1972 Teleseismic residuals at LASA-USGS extended array and their interpretation in terms of crust and upper mantle structure; J. Geophys. Res. 77 1503-1527

Jones T D and Nur A 1982 Seismic velocity and anisotropy in mylonites and the reflectivity of deep crustal faults; Geology 10 260-263

Jordan T H and Frazer L N 1975 Crustal and upper mantle structure from Sp phases; J. Geophys. Res. 80 1504-1518

Kind R, Kosarev G L, Makeyeva L I and Vinnik L P 1985 Observation of laterally inhomogeneous anisotropy in the continental lithosphere; Nature (London) 318 358-361

Mezger K, Bohlen S R and Hanson G N 1990 Metamorphic history of Archaean Pikwitonei Granulite Domain and cross lake subprovince, superior province, Manitoba Canada; J. Petrol. 31 483-517

Mishra D C 1990 Precambrian rifts and associated tectonics of Peninsular India, in Precambrian continental crust and its economic resources. (ed) S M Naqvi (Holland: Elsevier), Developments in Precambrian Geology 8 487-502

Naha K, Srinivasan R and Jayaram S 1991 Sedimentological, structural and migmatic history of the Archaean Dharwar Province, south India; Proc. Indian Acad. Sci. (Earth Planet. Sci.) $100413-433$

Newton R C and Perkins D 1982 Thermodynamic calibration of geobarometers based on the assemblages garnet-plagioclase-orthopyroxene-(clinopyroxene)-quartz, Am. Mineral. 67 203-222 
Newton R C and Hansen E C 1986 The South India - Sri Lanka high grade terrain as a possible deep crust section; In: The nature of the Lower Continental Crust, Geol. Soc. (London) Supl. Pub. 24 297-307

Nicolas A and Christensen N I 1987 Formation of anisotropy in upper mantle peridotites - a review; In: Composition, structure and dynamics of the lithosphere - asthenosphere system. (eds) $\mathbf{K}$ Fuchs and C Froidevaux, Washington D. C., American Geophysical Union. Geodynamics Series 16 111-123

Owens T J 1987 Crustal structure of the Adirondacks determined from Broadband teleseismic waveform modelling; J. Geophys. Res. 92 6391-6401

Peseckis L L and Burdick L J 1982 Station site characteristics of WWSSN stations in India and southern Asia; Bull. Seism. Soc. Am. 72 1207-1218

Pichamuthu C S 1953 The charnockite problem; Mys. Geol. Assoc., Bangalore

Ramesh D S, Prakasam K S, Makeyeva L I, Vinnik L P and Gaur V K 1990 First report on continental anisotropy in the south Indian shield; Geophys. J. Int. (under revision)

Rao P S 1978 Some aspects of structure and tectonics of Kerala règion, India and related mineralisation; In part III Geol. Surv. India. Misc. Publ. No. 34 51-64

Rai S S, Srinagesh D and Gaur V K 1992 Granulite evolution in South India - A seismic tomographic perspective; J. Geol. Soc. India (in press)

Siegesmund S and Kern H 1990 Velocity anisotropy and shear wave splitting in rocks from the mylonite belt along the Insubric Line (Ivrea zone, Italy); Earth Planet. Sci. Lett. 99 29-47

Silver P G and Chan W W 1988 Implications for continental structure and evolution of seismic anisotropy; Nature (London) 335 34-39

Singh D D and Rastogi B K 1978 Crustal structure of the peninsular shield beneath Hyderabad (India) from the spectral characteristics of long period P-waves; Tectonophysics 51 127-137

Smith W D 1970 S to P conversion as an aid to crustal studies; Geophys. J. R. Astron. Soc. 19 513-519

Subba Rao D V 1987 Regional gravity and crustal structure; NGRI annual report 1986-87 16-17

Taylor S R and Toksoz M N 1979 Three-Dimensional crust and upper mantle structure of the northeastern United States; J. Geophys. Res. 84 7627-7644

Trumpy R 1980 Geology in Switzerland; (Basel: Wepf Co.)

Vinnik L P, Kosarev G L and Makeyeva L I 1984 Anisotropy of the lithosphere from the observations of SKS and SKKS; Proc. Acad. Sci. USSR (in Russian), 78 1335-1339

Vinnik L P, Kind R, Kosarev G L and Makeyeva L I 1989 Azimuthal anisotropy in the lithosphere from observations of long period S waves; Geophys. J. Int. 99 549-559

Wong Y K, Smithson S B, Zawislak R L 1982 The role of seismic modeling in deep crustal reflection interpretation; In part I: University of Wyoming contributions to Geology. 20 91-109 